\title{
Merging missions and methods: A study of restructuring and adaptation in nonprofit health care organizations
}

This article was published in the following Dove Press journal:

Journal of Healthcare Leadership

8 July 2010

Number of times this article has been viewed

\author{
Julie Pietroburgo' \\ Stephen P Wernet ${ }^{2}$ \\ 'Department of Public Administration \\ and Policy Analysis, Southern \\ Illinois University Edwardsville, IL, \\ USA; ${ }^{2}$ School of Social Work and \\ Department of Public Policy Analysis, \\ Saint Louis University, MI, USA
}

\begin{abstract}
Health care nonprofit organizations often approach change with a fundamental resistance based on a stalwart commitment to charitable missions and vulnerable clientele. Yet they are being forced to adapt as government devolution, increased competition, and greater demand for their services, threaten their resource bases. While health care nonprofits are joining forces to better accommodate their diminished resources, little is known about the manner, motivation, and impacts of restructuring and adaptation. This study examines restructuring through review of collaborative activities in nonprofit hospices. Using a theoretical framework of political economy, 250 nonprofit hospices operating within a six-state region were surveyed regarding their restructuring experiences in order to understand why and how restructuring takes place. Results indicate that organizations that restructure have strong economic bases and pursue restructuring as a way of achieving greater financial stability. The demographic characteristics of age and size were found to be predictive of decisions to join forces with restructuring, most commonly impeded by internal political factors, including differences in management, governance, and structure. Finally, the study found that restructuring was perceived as fulfilling its promise through the enhanced economic and political status of organizations.
\end{abstract}

Keywords: nonprofit restructuring, mergers, alliances, collaboration, adaptation

\section{Introduction}

Leaders of nonprofit health care organizations are being forced to "face the music". Forces originating in the economic, competitive, and political environments are compelling leaders to consider options for organizational sustainability, change, and survival. In economic terms, retrenchment in public funding and a deeper penetration of the market culture is undermining the operational capacity and financial viability of many organizations. Consequently, these organizations are becoming more unstable. ${ }^{1,2}$ Government support has been constrained, the proportion of financial assistance provided through charitable or philanthropic contributions has declined, and there is a continuing commercialization of the sector. ${ }^{3,4}$

In addition, health care nonprofit organizations are encountering change on the competitive front. Many organizations historically maintained a near monopoly in serving a targeted need, territory, and populace. However, in the past 25 years, heightened demand for service has prompted dramatic growth in the sector. ${ }^{1,5-7}$ Contemporary organizations frequently overlap in services, territories, and missions. Competition with other nonprofit organizations, as well as for-profit and governmental providers, has posed a challenge for struggling organizations to meet their program goals.
Correspondence:J Pietroburgo Department of Public Administration and Policy Analysis, Southern Illinois University Edwardsville,

Illinois 62026, USA

$\mathrm{Tel}+\mathrm{I} 6186503762$

Fax +l 6186502786

Email jpietro@siue.edu 
Concurrently, political forces are shifting and contemporary public policy towards nonprofit organizations has become confused. ${ }^{6,8}$ Government subsidizes the activities of nonprofit organizations while simultaneously placing limits on their actions. Political uncertainty results in confusion and discontinuity in nonprofit service provision.

As a result of pressures in these three environments, leaders in nonprofit health care organizations are pursuing numerous alternative responses. Some are following an organizational path that involves internal restructuring, including the realignment of organizational governance, decision-making structures, and internal resource allocations. ${ }^{9}, 10$ Others are choosing to create new external relationships and alignments with other organizations to enhance access to vital resources, ${ }^{10,11}$ while some organizations are holding fast to their present positions.

The purpose of this study was to answer two questions. Firstly, why do nonprofit health care organizations restructure? The research examined the relationship between organizational characteristics and context in the decision to restructure, including the significance of financial, competitive, and political forces in motivating decisions to restructure. Secondly, how do nonprofit health care organizations restructure? The research examined the process of restructuring and the forms of restructuring, as well as the political and economic pressures in the environment that facilitate and impede restructuring.

\section{Literature review}

Theories that explain why and how nonprofit organizations restructure can be grouped into two clusters. ${ }^{910,12-16}$ In one cluster, the selection or ecological perspective holds that organizational change occurs at a macrosociologic level of the population and is compelled by external forces. Some organizations fail to change or modify their structures because of both internal and external limits, ie, populations of organizations are driven to adaptation or extinction due to changing environmental conditions over which the organizations have little or no control. Those that survive have organizational characteristics that support an effective response to environmental change. Inertial pressures arise from both environmental constraints and internal arrangements that frequently prevent organizations from changing structures, instead opting for the status quo.

In the other cluster, the adaptive or anticipatory perspective depicts organizations as active agents determining their own fate. They are proactive and deliberate in their planning, and are attuned to the need for change in response to perceived threats, vulnerabilities, and opportunities. Engaged and strategic organizations succeed while those that are not fail. Organizations with strong and plentiful resources prosper whereas ones with inferior resources falter.

The explanatory shortfall in both clusters is one of unidimensionality. Both sets of theories depict nonprofit organizational restructuring in simplistic terms and through monocular lenses. They miss the subtleties and complexities of the world within which nonprofit organizations operate. Galaskiewicz and Bielefeld ${ }^{17}$ have suggested that an integrated theoretical approach is required for recognizing the inherent complexity and dynamism facing nonprofit organizations and compelling their change. One such integrated theory is political economy which applies the theoretical perspectives of both adaptation and selection in ways that are useful for analyzing organizations.

\section{Political economy: an integrative theory}

Designed to bring analytic order to a myriad theoretical approaches, political economy provides an integrative framework for studying the political and economic environments of organizations. ${ }^{18}$ It is a dynamic theory reflecting the complexity of organization life and environments as depicted in Table 1. In explaining why and how organizational change occurs, political economy considers four sets of factors, ie, external economy, external polity, internal economy, and internal polity.

\section{External economy}

Political economy recognizes the impact of external factors on organizational behavior. The external economy is the productive exchange system of the organization and encompasses input characteristics (labor, material, technology, facilities, and cost factors), output characteristics (market demand and channels), as well as the structure of the industry. Organizations are seen as externally constrained by their dependence on the environment for necessary resources. Organizational change can be driven by the external economy, in particular, the resources required to underwrite the organization's operations. The need for vital resources from external sources can drive organizational behavior and decision-making when shifts in resources stimulate organizational response. However, financial resources are not the sole driver within the external economy. Other tangible resources, such as the availability of paid and volunteer labor, technology, and materials contribute to the composition of an organization's external economy. ${ }^{18}$ 
Table I Political economy framework ${ }^{18}$

\begin{tabular}{|c|c|c|}
\hline & $\begin{array}{l}\text { External environment } \\
\text { structure and process }\end{array}$ & $\begin{array}{l}\text { Internal structure } \\
\text { and process }\end{array}$ \\
\hline Polity & $\begin{array}{l}\text { - Regulatory bodies } \\
\text { - Competitors } \\
\text { - Interest groups/supports } \\
\text { - Media/communications } \\
\text { - Interested and } \\
\text { potentially interested } \\
\text { citizenry }\end{array}$ & $\begin{array}{l}\text { - Governance } \\
\text { - Management } \\
\text { - Staff } \\
\text { - Mission } \\
\text { - Culture, norms, and } \\
\text { values } \\
\text { - Structure }\end{array}$ \\
\hline Economy & $\begin{array}{l}\text { - Financial resources } \\
\text { - Operating inputs: labor, } \\
\text { facilities, supply, } \\
\text { volunteers and cost } \\
\text { factors } \\
\text { - Output characteristics: } \\
\text { referrals, census, and } \\
\text { demand factors } \\
\text { - Industry structure } \\
\text { - Macroeconomic effects } \\
\text { on supply-demand } \\
\text { - Geographic factors }\end{array}$ & $\begin{array}{l}\text { - Operating procedures } \\
\text { - Allocation rules; } \\
\text { accounting and } \\
\text { information systems } \\
\text { - Task and technology } \\
\text { related unit } \\
\text { differentiation } \\
\text { - Incentive system; pay, } \\
\text { promotion, tenure, and } \\
\text { fringe benefits } \\
\text { - Service scope } \\
\text { - Service responsiveness }\end{array}$ \\
\hline
\end{tabular}

\section{External polity}

The external polity focuses on the power and influence structures outside of the organization with which the organization must contend, and within which it must operate. External polity is comprised of the organization's external network of stakeholders, its competitors, and the authoritative bodies that impact its delivery of goods and services. The external polity consists of individuals and groups who are interested, or potentially interested, in the work of the organization. ${ }^{18}$

\section{Internal economy}

Simultaneously, political economy acknowledges the significance of internal forces in compelling organizational behavior. The internal economy consists of the goods and services produced and the organizational forms, mechanisms, rules, and institutions through which they are produced and exchanged. These include operating procedures, programmatic services and offerings, task assignment, resource allocation and accounting systems, pay structures, and technological tools. ${ }^{18}$

\section{Internal polity}

The internal polity incorporates the ethos and values of the organization, relates to issues of power distribution and legitimacy, and is embodied in the distribution of internal decision-making authority. The internal polity includes governance policies and practices, management and staff operations, and political processes within the organization. The decision-making capacity of an organization may either initiate or impede change. The decision-making style as well as the internal resource base of an organization determines the ultimate restructuring action that is taken. Organizations may change in anticipation of or in response to opportunity and risk. However, proactive adaptation may be inhibited if internal political forces are not supportive of change. ${ }^{18}$

\section{Interactions and organizational change}

Political economy also emphasizes the interlocking nature of these four factors. It depicts the internal and external forces of polity and economy as dynamic, interactive, and complex, ie, iterative and recursive. At any given moment, the four factors are in flux, expanding or contracting in response to the interplay among the factors. Change in one factor often produces opportunities, challenges, and demands within another factor. As the external economy constricts (eg, diminution of market demand for an organization's services), an organization may be compelled to draw upon alternative resources from another factor (eg, appeal to political bases to change regulations that inhibit marketing opportunities). How an organization responds, including the refusal to allow change, is a function of the balance among its four factors. An organization may be constrained by its dependence on the environment for necessary resources. Many organizations delay response, and some refuse to respond, to change in the politicoeconomic environment. Many attempt to manage their dependencies through adaptive strategies. ${ }^{19}$

Among the adaptive strategies available to organizations is restructuring. Kohm et a ${ }^{20}$ suggest that restructuring should be viewed as a continuum progressing from collaboration to alliance to integration. Collaboration involves arrangements where there is no permanent organizational commitment, decision-making continues to reside with the individual organizations, and a low degree of formality and structure are attendant. Examples of collaboration are joint fundraising or public relations campaigns. Alliance offers a middle-ground position involving cooperation for the foreseeable future and shared decision-making. Alliances are formalized arrangements that are agreement-driven, include administrative consolidations (where specific functions are mutually supported by the participating organizations), and joint programming (involving the shared provision and management of common programs and services). Integration involves changes to 
corporate control and creation of a new organizational entity. Integration commonly includes mergers, establishment of management service organizations, and parent-subsidiary structures.

For this study, political economy provided the theoretical framework for understanding and explaining the degree to which internal and external factors of economy and polity influence nonprofit organizational restructuring. This framework provides a foundation for exploring the first research question, ie, why do nonprofit organizations restructure?

The four factors in political economy suggest certain directions of change and their effects. Specifically, organizations that restructured were hypothesized to face greater challenges in their external environments, such as compromised external economic positions (inadequate financial resources, labor shortages, few referral sources, and insufficient demand), and weakened political bases (limited external visibility, intrusive regulatory environments, and significant competition). Further, the adaptive qualities and the decision-making capacity within the organizations would determine whether they moved forward or maintained the status quo in the face of diminished political and economic resources. Thus, those organizations that restructured were expected to have boards and executive leadership more adaptive in their actions than would be found in organizations opting for the status quo. Finally, it was hypothesized that, despite external factors that would appear to compel restructuring, internal inertial forces of a political nature would prevent many organizations from undertaking any substantive action.

In addressing the second research question of how nonprofit organizations restructure in response to political and economic pressure in the environment, the restructuring options posited by Kohm et $\mathrm{al}^{20}$ were utilized. Organizations in a threatened position due to diminished resource bases were expected to opt for the more drastic restructuring measure of integration, while stronger organizations seeking only to enhance their resource bases would choose the shorter term and less formal options of collaboration and joint ventures.

\section{Methods}

\section{Sample}

Nonprofit hospice organizations were selected as the sampling frame for this study because the hospice movement is representative of many of the distinctive ideological and structural characteristics of the broader nonprofit sector and especially those operating in the health care field. Introduced in this country in 1978, hospices arose from volunteer origins rooted in a mission of charitable care for the destitute dying. Contemporary hospices operate with a novel mix of public funding, volunteer manpower, professional guidance, and community-based charitable support. More than 4700 hospice programs exist throughout the US, and over 1.4 million patients received care in 2007. In 1998, Boling and Lynn ${ }^{21}$ reported that new hospice programs were being organized at an average rate of 100 to 150 per year, a pace that has only accelerated in the past 10 years. Over $48 \%$ of hospices function as nonprofit entities. ${ }^{22}$

Similar to other nonprofits, hospices are facing a host of economic, political, and competitive pressures that prompt consideration of restructuring. The Medicare Hospice Benefit, enacted by Congress in 1982, is the dominant source of payment for hospice care. In 2007, 83.6\% of hospice patient expenses were covered by the Medicare Hospice Benefit. The percentage of patient days covered by the Medicare Hospice Benefit was 87.0\%. ${ }^{22}$ However, hospices are finding their financial positions threatened as the federal government seeks to devolve and reduce funding for end-oflife care. ${ }^{23}$ The federal government has tightened the criteria for hospice enrollment, requiring greater justification and clinical documentation of a patient's terminal diagnosis, while seeking to change Medicare and Medicaid programs from primarily fee-for-service to managed care reimbursement. ${ }^{24,25}$ Finally, end-of-life care has grown more competitive with the emergence of national for-profit groups and the development of hospice units in hospitals, nursing homes, and home health care companies. ${ }^{23}$

While forces confronting hospices are similar in many respects to those faced by a wider array of organizations in the health care and social welfare fields, some pressures may be unique to the organizational type and milieu. For example, hospices fall into that subset of nonprofits that are contract-driven, rather than solely volunteer-based, and have highly regulated and monitored operations. Further, the growing degree of for-profit competition, increased professionalism in the end-of-life care movement, and growing visibility and public debate over assisted suicide are factors that differentiate the hospice field.

The study employed a purposive sample of six states, ie, Kansas, Illinois, Indiana, Iowa, Michigan, and Missouri. These states were selected because they provided a deliberately diverse and representative sample of hospice agencies with respect to factors of geography (urban/rural/suburban), organizational age, organizational size (budget and clientele), political environment, and degree of competition. Within each of those six states, the universe of nonprofit hospices was surveyed, yielding a census population of $250($ Kansas $=22$, 
Illinois $=62$, Indiana $=32$, Iowa $=48$, Michigan $=61$, and Missouri $=25$ ). Surveys were directed to executive directors of the organizations.

This study was conducted using two sample panels over two time periods. The objective of this two-panel approach was to compare changes in reorganization efforts over time. In the first panel in 2002, surveys were mailed to the 250 hospice organizations. In total, 124 of the 250 organizations completed and returned a survey (response rate 49.6\%). In 2008 , the objective was to resurvey all the original survey respondents, however, valid addresses (mail and electronic) could be found for only 80 of the organizations. Of the 80 hospices to which surveys were sent, 12 responded (15\% response). Given the low response rate in the 2008 panel, the results from that study must be interpreted with considerable caution. The 2002 panel study also included qualitative assessment of factors influencing reorganization based on targeted interviews and document review of six individual hospice organizations, the results of which have been published in other hospice and nonprofit publications. ${ }^{26,27}$

\section{Procedure}

The research design for this study was quantitative-descriptive in its use of statistics to define characteristics of study participants. The study utilized a cross-sectional, panel-survey design to assess organizational factors of political economy contributing to decisions regarding restructuring.

The study employed one dependent variable, ie, the organizational decision to restructure. Three levels of the dependent variable were identified, ie, restructure (organizations that consider restructuring and follow through on plans to implement changes), consideration (organizations that consider restructuring but ultimately do not implement the changes), and no consideration (organizations that never consider restructuring). In addition, the type of restructuring action was further delineated between integration, alliances, and collaborations.

Based on the political economy framework, the independent variables included internal polity, external polity, internal economy, and external economy. Using this framework, the study examined the association between the strength of the organization's resource bases and the decision to restructure (the impact of the organization's external polity and economy on its internal polity and economy) and the association between the decision-making capacity within the organization and the decision to restructure (the recursive relationship within the internal polity and economy).
For the purposes of the study, the four factor sets of political economy were translated into observable terms specific to the organization's context. Political and economic resource bases were operationalized as weak, moderate, or strong. Decision-making capacity was characterized as adaptive, passive, or reactive, based on past responses to external and internal change. Operational definitions provided clarity and consistency for respondents in assigning a quantitative rating to the relevant variables.

\section{Instrumentation}

The research instrument was a self-administered survey specifically designed for this study, and comprised questions covering experience of the agency with restructuring activities, factors that impacted restructuring decisions (specifically related to resource bases and decision-making capacity), factors that impeded restructuring decisions (for example, impediments of a structural, legal, informational, cultural, or political nature), and demographic profile of the hospice organization.

Survey questions utilized Likert-type scales and multiple-choice items. Questions of an attitudinal nature employed a Likert-type scale with five ratings. Respondents rated organizational characteristics as either: " 1 " strong and contributing to organizational stability and growth (rating of 4 or 5); "2" moderate and having a neutral effect on organizational stability and growth (rating of 3); or " 3 " weak and detracting from organizational stability and growth (rating of 1 or 2). Respondents also assigned ratings by level of agreement ( 5 = "strongly agree", 1 = "strongly disagree") with statements depicting alternative adaptive, reactive, and passive actions that board and management could adopt in response to environmental pressures. Finally, multiple-choice items were used to categorize demographic data relating to the budget size, organizational age, structure, geography, and clientele of the agency, including pre- and postrestructure status of the organization. Measurement error was minimized by field-testing of the survey instrument with a sample of executive directors and board members of six hospices operating in a combination of rural and suburban settings.

\section{Data analysis 2002 survey results}

Survey responses were statistically analyzed using descriptive statistics as well as $t$-tests, analysis of variance, and correlation coefficients to describe restructuring characteristics of the respondent groups. Political economy was used as an organizing heuristic for identifying and 
examining all the factors that compelled and impeded organizational restructuring and also served as the basis for constructing the survey questions. Factors were identified that reflected internal and external polity and economy, as noted in Table 2. Based on survey responses, these factors then formed an index of an organization's relative strength or weakness and decision-making style along the four quadrants of political economy.

Factor analysis was attempted to identify the political economy factor categories. However, because the factor analysis solution was unsuccessful in producing such categories, a factor solution based on the conceptual framework was constructed.

A factor-like solution was used in the data analysis. Questionnaire items were assigned to one of the four political economy quadrants based on conceptual analysis. Data analysis focused on how and why the varied restructuring outcomes occurred among the respondents. Pattern matching for rival explanations was also employed to facilitate the comparisons of empirically-based patterns emerging from the quantitative research with predicted patterns. ${ }^{28}$ The goal was to determine if a pattern of mutually exclusive independent variables existed with each of the three respective restructuring outcomes.

ANOVA was used to examine the relationship of political economy factors to the restructuring decision. First, factors were studied across broad decision sets (for example, comparisons of those that restructured, those that considered restructuring, and those that did not consider restructuring), as well as across specific types of restructuring action

Table 2 Operationalization of political economy

\begin{tabular}{|c|c|c|}
\hline Variable & Conceptual component & Operational question \\
\hline \multirow[t]{10}{*}{ Internal polity } & - Mission & - Are management practices sound? \\
\hline & - Governing practices & - Is board leadership strong? \\
\hline & - Management style & - Is there support for restructuring among staff? \\
\hline & - Culture & - Is there support for restructuring within the board? \\
\hline & - Leadership style & $\begin{array}{l}\text { - Is there support for restructuring within } \\
\text { management? }\end{array}$ \\
\hline & - Staff, board, and management support & - Is culture conducive to restructuring? \\
\hline & & - Does mission support restructuring? \\
\hline & & - Is organizational structure compatible with \\
\hline & & restructured arrangement? \\
\hline & & - Are governing practices conducive to restructuring? \\
\hline \multirow[t]{6}{*}{ External polity } & - Regulatory oversight & - Is competition increasing or decreasing? \\
\hline & - Community visibility & - How visible is agency in the community? \\
\hline & - Support of donors & - Is donor support strong? \\
\hline & - Support of funding bodies & - Is regulatory compliance manageable? \\
\hline & - Relationship with other organizations & - Are legal issues a concern? \\
\hline & - Degree of competition & \\
\hline \multirow[t]{5}{*}{ Internal economy } & - Operating procedures & - Is service array growing or declining? \\
\hline & - Operating efficiency & - Is service responsiveness satisfactory? \\
\hline & - Operating costs & - Are operating costs increasing or decreasing? \\
\hline & - Service responsiveness & - Is there service duplication? \\
\hline & - Array of services & $\begin{array}{l}\text { - Are operating procedures cost-effective and } \\
\text { efficient? }\end{array}$ \\
\hline \multirow[t]{6}{*}{ External economy } & - Financial position & - Is daily census declining, stable, or growing? \\
\hline & - Geographic scope & - Is volunteer support sufficient? \\
\hline & - Volunteer resources & - Is financial status declining, stable, or growing? \\
\hline & - Funding availability & - Are referral sources declining, stable, or growing? \\
\hline & - Referral sources & \\
\hline & - Census levels & \\
\hline
\end{tabular}


(for example, comparisons of those that integrated, those that formed alliances, and those that collaborated). In addition, within-subjects factors were examined through mixed model analyses of variance. In this way, the significance of political economy factors within discrete restructuring types was studied. For example, political economy factors were uniquely examined for those that integrated, those that collaborated, and those that formed alliances.

\section{8 survey results}

As previously noted, the respondent base from the 2002 survey formed the sample base for the 2008 research. However, while 124 organizations responded to the 2002 survey, valid addresses (mail and electronic) could be found for only 80 of these same organizations in 2008. This may be reflective of changes in ownership, name, or relocation in the intervening six years. Of the 80 hospices to which surveys were sent, 12 responded (15\% response). Due to the low number of responses from the 2008 survey, no statistical tests were conducted with the data. Rather, a qualitative assessment was conducted of the change in conditions between 2002 and 2008 for the hospices responding to both surveys.

\section{Results}

\section{Restructuring as an organizational response}

A key finding emerging from the study was that most organizations do not pursue or even consider restructuring as a strategic option. The 2002 survey results showed that the majority of hospices $(52.2 \%)$ had never considered or attempted restructuring of any kind. This response increased in the 2008 survey to $87.5 \%$. For most organizations, restructuring remains an unfamiliar and untested response. Among those that did restructure prior to 2002, collaborations were the most prevalent form, with 38\% adopting that approach. Twenty-one percent of respondents that restructured had integrated, and $10 \%$ had been involved in an alliance. Interestingly, $31 \%$ had been involved in multiple forms of restructuring suggesting that experience with one form of restructuring may lay the groundwork for further efforts. Of the respondents in 2008, one organization restructured by forming an alliance with another nonprofit organization. Again, the primary restructuring choice of respondents was one that maintained the independence of the organization.

In 2002, organizations that pursued restructuring had three organizational characteristics that showed some predictive relationship with restructuring action. Specifically, the restructuring decision was related to the size of the organization's budget ( $r=0.273, P<0.01$ ), daily patient census $(r=0.237, P<0.05)$, and the age of the organization $(r=0.192, P<0.05)$. Older and larger organizations were more likely to engage in some form of restructuring action.

Regarding the specific restructuring alternatives (integration, alliance, or collaboration), other significant correlations were discovered. Integrations were preferred by organizations with larger budgets $(r=0.397, P<0.01)$ and with a higher average daily patient census $(r=0.337$, $P<0.05)$. Collaborations were preferred by organizations with smaller budgets $(r=-0.309, P<0.05)$ and with a lower average daily census $(r=-0.337, P<0.05)$. Alliances were preferred by older organizations $(r=0.341, P<0.05)$.

Neither of the other demographic factors of ownership status (freestanding or a division of a broader health care organization) and geographic placement (rural, suburban, urban) showed a statistically significant relationship with restructuring action. However, based on descriptive statistics, rural organizations were more inclined to engage in collaboration than other forms of restructuring. Hospices operating in the urban and suburban settings showed no marked preference for a particular form of restructuring.

\section{Why organizations restructure}

In the 2002 survey, a number of questions assessed why organizations choose restructuring. Based on the theoretical framework, organizations were asked to assess their organizational strength along the four factor sets of the political economy. With respect to most political and economic factors, no statistically significant difference was found between those that restructured and those that did not restructure.

Univariate analysis of variance indicated no statistically significant differences between groups (those that restructured, those that considered restructuring, and those that never considered restructuring) in their assessments of pre-restructure status as noted in Table 3. These results indicate that regardless of their eventual engagement in restructuring, organizations had a similar assessment of their organizational strengths and weaknesses. The external economy factor set approached statistical significance $(P=0.058)$ when comparing organizations that never considered restructuring with organizations that restructured. Those organizations that restructured ranked their pre-restructure status stronger on the external economy factor set than did those that never considered such actions (mean difference $=-0.335$ ). This indicates that organizations that restructured perceived themselves as operating from solid economic positions. Those that never considered restructuring 
Table 3 Differences in pre-restructure self-assessment by organizations*

\begin{tabular}{lcll}
\hline Group comparison & $\begin{array}{l}\text { Mean } \\
\text { difference }\end{array}$ & $\begin{array}{l}\text { Standard } \\
\text { deviation }\end{array}$ & $\begin{array}{l}\boldsymbol{P} \\
\text { value }\end{array}$ \\
\hline Did not consider-considered & & & \\
External economy & -0.242 & 0.2014 & 0.490 \\
External polity & 0.290 & 0.2093 & 0.386 \\
Internal economy & 0.123 & 0.2179 & 0.854 \\
Internal polity & 0.136 & 0.2453 & 0.858 \\
Did not consider-restructured & & & \\
External economy & -0.335 & 0.1385 & 0.058 \\
External polity & 0.126 & 0.1439 & 0.682 \\
Internal economy & 0.270 & 0.1498 & 0.203 \\
Internal polity & 0.276 & 0.1692 & 0.269 \\
Considered-restructured & & & \\
External economy & 0.360 & 0.2014 & 0.898 \\
External polity & 0.164 & 0.2093 & 0.735 \\
Internal economy & -0.147 & 0.2179 & 0.797 \\
Internal polity & -0.140 & 0.2446 & 0.849 \\
\hline Notes Mean scors bsed
\end{tabular}

Notes: "Mean scores based on five-point Likert-type scale $(5=$ "strongly agree", $\mathrm{I}=$ "strongly disagree"). ${ }^{*} \mathrm{P}<0.05$.

exhibited the lowest mean scores in this area indicating that they operated from weaker perceived positions on external economy factors which may have inhibited their pursuit of or opportunities for restructuring.

Within respect to internal polity, the survey asked hospice executive directors to evaluate the decision-making style employed within their organizations as they confronted changes in environmental conditions. It was hypothesized that those organizations that restructured would display adaptive characteristics, while those organizations that only considered or never-considered restructuring would exhibit reactive or passive approaches.

Results of one-way ANOVA showed no statistically significant differences across organizational groups (restructured, considered, and did not consider) in the dominant decision-making styles employed. Based on their self-perceptions of adaptive qualities within their organizations, respondents across categories viewed the predominant decision-making style employed within the organization as adaptive. This was contrary to the hypothesis that there would be differences in decision-making styles across restructuring outcomes.

However, comparison of mean scores showed a difference between the styles of the board and the executive director in the manner in which they approached change (see Table 4). Organizations that did not consider restructuring regarded both the executive director and the board as predominantly adaptive in approach but with neither seeing a compelling need for restructuring. Organizations that restructured and
Table 4 Dominant decision-making styles*

\begin{tabular}{|c|c|c|c|}
\hline Decision-maker & Restructured & Considered & Did not consider \\
\hline Executive director & $A=4.50$ & $A=4.38$ & $A=4.26$ \\
\hline Board of directors & $R=3.63$ & $R=3.46$ & $A=3.39$ \\
\hline
\end{tabular}

those that considered restructuring viewed the dominant decision-making style of the executive director as adaptive, whereas the board was seen as predominantly reactive. In effect, executive directors were perceived as leading the board in consideration of the restructuring option.

Survey questions also examined the process of restructuring and the forms of restructuring which nonprofit organizations undertake. Specifically, the survey addressed the significance of political and economic factors in forming an alternative structure. In the 2002 survey, ANOVA results showed no political or economic factors as being statistically significant to the form that the organization used to restructure. However, descriptive statistics as reported in Table 5 were of interest. Survey responses showed that motivations for restructuring differed according to the type of restructuring (integration, collaboration, or alliance). For those organizations that integrated, internal factors (political and economic) were dominant motivators including the desire to enhance operating efficiencies and service provision. For those organizations that formed a collaborative, similarity of mission (an internal political factor) ranked as the most important reason to restructure.

Table 5 Reasons for restructuring in 2002

\begin{tabular}{|c|c|c|c|}
\hline & Integration & Alliance & Collaboration \\
\hline \multicolumn{4}{|l|}{ External political } \\
\hline Increase visibility & 3.5 & $3.93(3)$ & $4.04(2)$ \\
\hline Established relationships & 4.0 & $3.86(4)$ & $4.04(3)$ \\
\hline \multicolumn{4}{|l|}{ Internal political } \\
\hline Similar missions & 4.0 & 4.07 (I) & $4.15(1)$ \\
\hline Support of board & $4.13(4)$ & 3.43 & 3.58 \\
\hline Support of management & $4.19(3)$ & 3.64 & 3.65 \\
\hline \multicolumn{4}{|l|}{ External economic } \\
\hline Similarity in geography & 4.06 & 3.29 & $3.88(4)$ \\
\hline Attract new referrals & 4.13 & 3.79 & $3.88(4)$ \\
\hline \multicolumn{4}{|l|}{ Internal economic } \\
\hline Service enhancement & $4.31(2)$ & 2.86 & 3.35 \\
\hline $\begin{array}{l}\text { Enhance operating } \\
\text { efficiencies }\end{array}$ & $4.38(I)$ & $4.0(2)$ & 3.35 \\
\hline
\end{tabular}

Notes: Mean scores were based on a five-point Likert-type scale $(5=$ "strongly agree", I = "strongly disagree"). Of the 26 possible reasons for restructuring offered, the Table contains only the top four factors cited by respondents for each type of restructuring in 2002. Numbers reported in parentheses represent the within-group ranking of the reason for restructuring. 
External political and economic factors completed the motivators for collaborative restructures. These included increased visibility, established relationships between organizations, attraction of new referrals, and serving similar geographic areas. For those organizations that formed an alliance, restructuring motivators centered upon political factors (external and internal), complemented by external economic issues. Alliances were motivated by similarity in organizational mission, and a desire to enhance operating efficiencies, increase community visibility, and establish relationships with another organization.

\section{Why organizations do not restructure}

Survey questions also examined factors that preclude organizations from restructuring. In 2002, as indicated in Table 6, internal polity factors were the overwhelming impediments in restructuring. For those that considered integrating, the reasons for not going forward were related to differences between organizations in management styles and governing practices, no perceived need, and a desire to remain independent. Mixed-model analyses of variance with factor sets (internal economy, internal polity, external economy, external polity) as the within-subjects variables were conducted to determine which factor sets were most important to the decision not to integrate. A significant multivariate main effect was found $(\mathrm{F}[3,16]=13.012, P<0.001)$. Follow-up pairwise com-

Table 6 Reasons for not restructuring

\begin{tabular}{|c|c|c|c|}
\hline & Integration & Alliance & Collaboration \\
\hline \multicolumn{4}{|l|}{ Internal political } \\
\hline No pressing need & $3.73(3)$ & 3.4 & $3.8(3)$ \\
\hline Differences in structure & 3.55 & $3.8(3)$ & $3.8(2)$ \\
\hline Differences in governance & $3.73(2)$ & 3.6 & $3.8(2)$ \\
\hline $\begin{array}{l}\text { Differences in } \\
\text { management }\end{array}$ & $4.0(1)$ & 3.2 & $3.8(2)$ \\
\hline Differences in culture & 3.55 & $4.0(2)$ & $3.8(2)$ \\
\hline $\begin{array}{l}\text { Desire to stay } \\
\text { independent }\end{array}$ & $3.64(I)$ & $4.40(1)$ & $4.9(1)$ \\
\hline $\begin{array}{l}\text { Opposition of } \\
\text { management }\end{array}$ & 3.36 & $3.6(4)$ & $3.6(4)$ \\
\hline \multicolumn{4}{|l|}{ External economic } \\
\hline $\begin{array}{l}\text { Differences in financial } \\
\text { position }\end{array}$ & 3.36 & 3.6 & 3.8 \\
\hline \multicolumn{4}{|l|}{ Internal economic } \\
\hline $\begin{array}{l}\text { Differences in operating } \\
\text { procedures }\end{array}$ & 3.27 & 3.4 & $3.8(2)$ \\
\hline $\begin{array}{l}\text { Concerns about service } \\
\text { responsiveness }\end{array}$ & 2.82 & 3. & $3.8(2)$ \\
\hline
\end{tabular}

Notes: Mean scores were based on a five-point Likert-type scale ( $5=$ "strongly agree", I = "strongly disagree"). Of the 26 possible reasons for restructuring offered, the Table contains only the top four factors cited by respondents for each type of restructuring in 2002. Numbers reported in parentheses represent the within-group ranking of the reason for restructuring. parisons indicated that internal polity $(\mathrm{M}=3.737, \mathrm{SD}=0.162)$ was more important than external economy $(\mathrm{M}=3.158$, $\mathrm{SD}=0.175)$ and internal economy $(\mathrm{M}=2.842, \mathrm{SD}=0.119)$. In addition, external economy was more important than external polity $(\mathrm{M}=2.776, \mathrm{SD}=0.148)$.

For those that considered forming an alliance, lack of action was attributable to the desire to remain independent, differences in organizational culture and structures, and opposition of management. Mixed-model analyses of variance with factor sets (internal economy, internal polity, external economy, external polity) as the within-subjects variables, were conducted to determine which factor sets were most important in the decision not to form an alliance. A significant multivariate main effect was found $(\mathrm{F}[3,6]=5.681$, $P<0.05)$. Follow-up pairwise comparisons indicated that internal polity $(\mathrm{M}=3.656, \mathrm{SD}=0.202)$ was more important than internal economy $(\mathrm{M}=3.156, \mathrm{SD}=0.159)$, and external polity, $(\mathrm{M}=3.111, \mathrm{SD}=0.200)$.

For those that considered forming a collaborative, restructuring again was impeded by a desire to remain independent, as well as concerns about service responsiveness, and differences in management style, culture, governing practices, and organizational structure. Management opposition to the collaboration also was a key issue. Again, mixed-model analyses of variance with factor sets (internal economy, internal polity, external economy, external polity) as the within-subjects variables, were conducted to determine which factor sets were the most important in the decision not to form a collaboration. A significant multivariate main effect was found, $(\mathrm{F}[3,4]=7.865, P<0.05)$. Follow-up pairwise comparisons indicated that internal polity $(M=3.300$, $\mathrm{SD}=0.346)$ was more important than external polity $(\mathrm{M}=2.679, \mathrm{SD}=0.302)$, and external economy was more important than external polity $(\mathrm{M}=3.286, \mathrm{SD}=0.434)$. In addition, internal economy $(\mathrm{M}=3.086, \mathrm{SD}=0.362)$ was more important than external polity $(\mathrm{M}=2.679, \mathrm{SD}=0.302)$.

\section{Impact of restructuring}

Finally, the survey examined the impact of restructuring as noted in Table 7. Among the 2002 respondents, it was reported that organizations that integrated reported improvements in financial status and expansion of referral sources. For those that formed alliances, agency visibility was perceived to increase. The positive impacts of collaboration were noted in improved service responsiveness, expansion of services, and enhanced visibility for the agency. Respondents across all groups noted that their missions were not altered by their restructuring actions. 
Table 7 Evaluation of restructuring outcome in 2002

\begin{tabular}{llll}
\hline & Integration & Alliance & Collaboration \\
\hline Financial status improved & $4.47(\mathrm{I})$ & 3.23 & 3.29 \\
Mission remained the & $4.47(\mathrm{I})$ & $4.15(\mathrm{I})$ & $4.17(\mathrm{I})$ \\
same & & & \\
Census increased & $4.33(2)$ & $3.46(4)$ & 3.46 \\
$\begin{array}{l}\text { Visibility increased } \\
\text { Service responsiveness }\end{array}$ & $3.87(4)$ & $3.46(4)$ & $3.75(3)$ \\
improved & 3.47 & 3.00 & $3.63(4)$ \\
$\begin{array}{l}\text { Services expanded } \\
\text { Referral sources }\end{array}$ & 3.67 & $3.46(3)$ & $3.79(2)$ \\
increased & $4.07(3)$ & $3.54(2)$ & 3.54
\end{tabular}

Notes: Mean scores were based on a five-point, Likert-type scale $(5=$ "strongly agree", I = "strongly disagree"). Of the 26 possible reasons for restructuring offered, the Table contains only the top four factors cited by respondents for each type of restructuring in 2002. Numbers reported in parentheses represent the within-group ranking of the reason for restructuring.

Univariate ANOVA tests were conducted to assess which type of restructuring had the greatest impact on organizational status and in what areas. Based on mean scores, a statistically significant difference $(P=0.046)$ existed in the post-restructuring status between those who integrated and those who formed alliances. Similarly, a marginally significant difference $(P=0.054)$ was found on internal polity with post hoc tests identifying the difference between integration and collaboration. These results showed that, with respect to factors in the external economy and internal polity, respondents viewed integration as having a more positive impact on their status than other forms of restructuring.

\section{Views of restructuring over time}

Results from the 2008 survey are useful insofar as they provide insight as to how organizations view the restructuring option over time. Three of the 12 respondents noted that they had considered restructuring and one had actually restructured prior to 2002. In the intervening 2002-2008 period, one additional respondent noted that their organization had considered restructuring but chose not to, and another respondent indicated that the organization had actually recently restructured by forming an alliance. Therefore, half of the respondents reported that their organizations had either considered or actually restructured at some time in the past.

In the 2008 survey, responses varied slightly from the earlier survey. Respondents identified four of the 10 elements from the original response set as reasons for restructuring, including similarity of organizational missions, enhancing operating efficiencies, maintaining/increasing census levels, and established relationships between organizations. Several different internal factors focusing on similarities between the organizations were offered as rationales to support the restructuring. These included similarities in operating procedures, governing practices, management styles, and financial pressures. Two external factors were also offered including increased competition and lack of support from external donors/funding sources. Unlike the 2002 respondents, the 2008 respondents identified increased competition as a major reason for pursuing restructuring, thereby reflecting a change in the operational environment.

Similar to 2002, organizations from the 2008 survey identified the absence of a pressing need as the major reason for not pursuing a restructuring. In addition, organizations cited as reasons for not restructuring the desire to maintain organizational independence, concern about service responsiveness, and differences between organizational governing practices and cultures. Unlike the first panel, the second offered some additional rationales for failing to pursue restructuring. These included differences in organizational missions, concerns about duplication of staff, lack of information to make the decision, and general concerns about the impact of joining organizations together.

Perhaps most interesting among the findings from the 2008 survey were the responses pertaining to the measurement of success in any restructuring. Similar to the earlier survey, respondents viewed success as including retention of organization mission, improved financial status, increased visibility, and reduced competition. However, the 2008 respondents also offered numerous other outcomes indicative of restructuring success, including increased donor support, attraction of new funding sources, and reduction in service duplication. Respondents indicated that they expected no change in referral sources or the organizational culture as a result of restructuring but did foresee an improved ability to address regulatory issues. Operating costs of the organization were not expected to be reduced due to the restructuring.

\section{Discussion}

This study sheds light on why and how nonprofit health care organizations approach restructuring as a strategic alternative, as well as the impacts of such actions. First, in answer to the question regarding why organizations restructure, the study found that most organizations do not. The study confirmed the findings of many earlier theorists that inertial forces are formidable and consequently most organizations opt for the status quo. In a complex field of financial, competitive, and political challenges, less than half $(47.8 \%)$ of the hospices chose any form of restructuring. Known, familiar, and predictable solutions and structures are preferable to the unfamiliar, even when they may be suboptimal by rational choice standards. 
Second, the application of the theoretical framework supported the findings of previous researchers ${ }^{17,29,30}$ regarding the dual roles of selectivity and adaptation in explaining why organizations restructure. The role played by adaptation can be seen in the restructuring action taken by the larger and older hospice organizations. The adaptive actions of restructuring occurred more often among those hospice organizations that operated from solid political and economic bases. Restructuring organizations tended to have larger budgets, more stable fiscal and volunteer resources, stronger referral bases, and greater demand for their services. These organizations pursued restructuring from positions of economic strength in an effort to achieve even greater financial stability. These larger and stronger organizations appear to be more strongly influenced by internal economy issues, eg, enhancing operating efficiencies and financial status of the organization. Larger organizations being more formal, bureaucratic, and professionalized require consistency of formal resources, ie, money to maintain operations. These larger, formal organizations rely upon econometric models for successful operations, rather than citizen participation and mutual aid models which are better suited for informal, grassroots, and small organizations.

The study also found that certain organizational characteristics may predispose an organization to restructuring action. Findings revealed the importance of organizational age in restructuring. Previous studies have asserted that older organizations tend to be more inert, and saddled with embedded bureaucratic structures and processes which render them less nimble in responding to environmental pressures. ${ }^{31,32}$ However, this study supports other work that suggests that rather than being a liability, organizational age can be an asset that facilitates adaptive strategies such as restructuring. ${ }^{29} \mathrm{Among}$ the hospices studied, descriptive statistics suggested that older organizations were the ones most receptive to and capable of restructuring. Age offered these older organizations several critical reserves unavailable to their younger counterparts, among them the confidence to take risks, capacity that could be dedicated to new possibilities, and an ability to read and respond to critical changes in their environments.

Selection forces were also important in explaining why organizations restructure. Haveman and $\mathrm{RaO}^{30}$ and Hager et $a l^{33}$ found that small organizations are more likely to be subject to selection pressures while larger organizations were more likely to undergo adaptation. Haveman and Rao ${ }^{30}$ found that rather than pursue the complicated and costly path of adapting to meet environmental contingencies, organizations tend to die out or, alternatively, create entirely new organizational entities to meet pressures better. Hager et $\mathrm{al}^{33}$ contend that younger organizations are smaller and more specialized, and therefore not as well connected to networks and resources which might present survival options.

Selection theory may also have explanatory value in the hospice field. Indeed, the rapid growth in the number of hospice organizations in the US and the relative youth of such organizations may be, in part, indicative of a predilection to start anew rather than reorganize and restructure existing agencies.

Findings from this study suggest that there are two factors which are prime motivations for restructuring. For both respondent panels, the desire to retain organization mission (an internal polity factor) drives the decision to restructure. In addition, an external economic factor (increased competition) serves as the "tripwire" for organizational attention and action. When financial pressures and operating efficiencies are added to increased competition, managers and leaders must attend to organizational structures, governance, and management. The results appear to point to external economic turbulence as the culprit, and incremental adjustments to internal organizational operations as the solution of first choice. In the event of a restructuring, the next important factor is pre-existing relationships with a potential partner, ie, an external polity factor. There is a preference for choosing a partner with whom one is familiar and has already worked.

Impediments to restructuring are largely attributable to internal polity factors. There is a strong desire to retain independence and, consequently, without significant pressure, organizations will not restructure. While organizations may have ample motivation for and opportunity to restructure, issues of a cultural nature (differences in mission, board and staff opposition, and governance philosophy) most often impede action. Internal opposition to restructuring trumps other factors, often leaving organizations stalemated, frustrated, and mired in repeated attempts to restructure. Nonprofit hospice organizations are commonly communityand grassroots-oriented, which fits with their strong desire to retain organizational autonomy.

Third, in answering the question of how organizations restructure, the study affirms the importance of decision-making capacity. The study found that organizational leaders view their decision-making styles as adaptive regardless of whether or not they engage in restructuring. While environmental contingencies may not lead all organizations to consider or implement restructuring, the decision-making style of the organization 
is nevertheless considered proactive, with executive directors seen as leading the board in varied steps on behalf of the organization. This set of findings suggests that the skills, capacities, and career goals of the executive director may play a role that is critical and determinative in organizational restructuring decisions. Decision-makers must possess sufficient knowledge about restructuring (and related processes such as how to conduct due diligence and assess impact) to proceed forward with deliberation. In pursuing restructuring options, it is also possible that these executive directors are merely presenting a picture of "being business-like". ${ }^{34}$ Further research is required to explore whether decision-making style attributed to these leaders is a reflection of the way they actually behave or merely the way they appear.

Fourth, different forms of restructuring appeal to different types of nonprofits, with organizations that are older and smaller in budget and census size favoring the less dramatic steps of alliance and collaboration, and larger organizations preferring to integrate. Not all forms of restructuring are viewed as equally beneficial or uncomplicated. While those attempting to restructure by integrations seek improvements predominantly in internal economy improvements, such as enhanced services and improved operating efficiencies, organizations that collaborate and form alliances hope to realize internal polity improvements, ie, meeting one's mission. Internal political economic factors drive restructuring decisions even though an external economic factor, ie, increased competition, may be the stimulus.

Finally, the study suggests that successful implementation of restructuring addresses all four quadrants of an organization's political economy. Foremost, the mission must be retained and maintained, while the culture is not affected negatively. That is, the internal polity of the organization must be unaffected. There should be improvement in the internal economy of the organization, ie, there are improvements in the organization's financial status, service responsiveness, and regulatory compliance, even though operating costs are unlikely to be reduced. Within the external polity, visibility should increase and referral sources should remain unchanged while census increases. Finally, within the external economy, there should be increased donor support and/or attraction of new funding sources.

\section{Implications for organizational practice}

In order to enhance organizational capacity in an increasingly competitive third sector, more nonprofit leaders are assessing the merits of joining forces with others. Consolidations and mergers in the private sector have also spurred interest in restructuring strategies among nonprofits. Yet, this study indicates that only a minority of nonprofit organizations actually engage in the process of restructuring. For most organizations, restructuring remains but one of the strategies available to address environmental turbulence and increased competition. In considering their options, organizations appear to employ an implicit cost-benefit analysis, and often conclude that the benefits of restructuring do not outweigh the costs. Organizations may be opting for other strategies to address environmental pressures including, among other things, internal reorganization, fundraising, downsizing, and changes in leadership or governance.

Further, this study suggests that where such restructuring is taking place, nonprofit leaders are not casually entering such arrangements. Restructuring is recognized as an adaptive strategy involving a substantial commitment of economic and political resources. For those that pursue such a course, the capacities and skills brought to the partnering table are critical to success. Experience, longevity, and financial stability all count in the restructuring equation.

Those nonprofit organizations that ultimately do move forward with restructuring are distinguished by the strength of their external bases of economic support and their ability to influence and manage their resource dependencies. They are in a position to either capitalize on restructuring options that are presented to them or create their own opportunities. While dependent on others for valuable resources, they have learned to navigate successfully their dependencies in ways that assure organizational growth. These organizations exhibit an adaptive decision-making style, while also having the internal reserves and experience to pursue collaborative arrangements.

Even among those that are well positioned, impediments are to be expected and more often than not the obstacles lie within. Internal politics in the form of board and staff opposition and differing cultures and governance must be acknowledged and resolved in order for the partnering arrangement to progress and endure. For those who successfully weather the partnering challenge, restructuring emerges as a positive strategy that yields perceived improvements in the economic and political position of the organization. As pressures intensify to garner limited resources in the nonprofit sector, it remains to be seen whether restructuring will gain acceptance as a valuable strategic response among organizations less favorably situated for change in volatile political and economic environments.

\section{Disclosure}

The authors report no conflict of interest in this work. 


\section{References}

1. Salamon L. America's Nonprofit Sector: A Primer. New York, NY: The Foundation Center; 1999.

2. Salamon L. The changing context of American nonprofit management. In: Robert D Herman and Associates, editors. The Jossey-Bass Handbook of Nonprofit Leadership and Management. 2nd ed. San Francisco, CA: Jossey-Bass; 2004

3. Díaz WA. The behavior of foundations in an organizational frame: A case study. Nonprofit and Voluntary Sector Quarterly. 1996;25:453-69.

4. Guo B. Charity for profit? Exploring factors associated with the commercialization of human service nonprofits. Nonprofit and Voluntary Sector Quarterly. 2006;35:123-38.

5. Salamon L, Sokolowski SW. Nonprofit organizations: New insights from QCEW data. Monthly Labor Review. 2005;128:9-26.

6. Sherlock MF, Gravelle JG. An Overview of the Nonprofit and Charitable Sector. Washington, DC: Congressional Research Service; 2009.

7. Wing K, Pollack T, Blackwood A. The Nonprofit Almanac 2008. Washington, DC: The Urban Institute Press; 2008.

8. Weisbrod B. The Nonprofit Economy. Cambridge, MA: Harvard University Press; 1988.

9. Pfeffer J. Organizations and Organization Theory. Boston, MA: Pitman Publishing Inc.; 1982.

10. Campbell D. Giving up the single life: Leadership motivations for interorganizational restructuring in nonprofit organizations. Adm Soc Work. 2009;33:368-86.

11. Arsenault J. Forging Nonprofit Alliances. San Francisco, CA: Jossey-Bass; 1998

12. Hannan M, Carroll G. Dynamics of Organizational Populations. New York, NY: Oxford University Press; 1992.

13. Hannan M, Freeman J. The population ecology of organizations. Am J Sociol. 1977;82:929-64.

14. Pfeffer J. Power in Organizations. Cambridge, MA: Ballinger Publishing Company; 1981.

15. Scott WR. Organizations: Rational, Natural, and Open Systems. 2nd ed. Englewood Cliffs, NJ: Prentice-Hall; 1992.

16. Shafritz J, Ott JS. Classics of Organization Theory. New York, NY: Harcourt Brace College Publishers; 1996.

17. Galaskiewicz J, Bielefeld W. Nonprofit Organizations in an Age of Uncertainty. Hawthorne, NY: Aldine De Gruyter; 1998.

18. Zald M. The Political Economy of Public Organizations. Lexington, MA: Lexington Books; 1973.

19. Pfeffer J, Salancik G. The External Control of Organizations: A Resource Dependence Perspective. New York, NY: Harper and Row; 1978.
20. Kohm A, La Piana D, Gowdy H. Strategic Restructuring: Findings from a Study of Integrations and Alliances among Nonprofit Social Service and Cultural Organizations in the United States. Chicago, IL: Chapin Hill Center for Children; 2000.

21. Boling A, Lynn J. Hospice: Current practice, future possibilities. Hosp J. 1998;13:29-32.

22. National Hospice and Palliative Care Organization. Hospice Statistics. Washington, DC: National Hospice and Palliative Care Organization; 2009.

23. Beresford, L. The future of hospice in a reformed American health care system: What are the real questions? Hosp J. 1997;12:85-91.

24. Mahoney J. Hospice and managed care. Hosp J. 1997;12:81-4.

25. Meier D. Restoring a balance: Approaches to improving palliative care. Paper presented at the National Hospice Organization Twelfth Senior Management and Leadership Conference, 1997 May, Washington, DC.

26. Pietroburgo J, Wernet S. Joining forces, fortunes and futures: Restructuring and adaptation in nonprofit hospice organizations. Nonprofit Management and Leadership. 2004;15:117-37.

27. Pietroburgo J. Joining forces, joining futures: Hospices at the crossroads. Am Journal Hosp Palliat Care. 2004;21:209-15.

28. Yin R. Case Study Research: Design and Methods. Thousand Oaks, CA: Sage Publications; 1994.

29. Chambre S, Fatt N. Beyond the liability of newness: Nonprofit organizations in an emerging policy domain. Nonprofit and Voluntary Sector Quarterly. 2002;31:502-24.

30. Haveman M, Rao H. Structuring a theory of moral sentiments: Institutional and organizational coevolution in the early thrift industry. Am J Sociol. 1997;102:1606-51.

31. Hannan M, Freeman J. Structural inertia and organizational change. Am Sociol Rev. 1984;49:149-64.

32. Minkoff D. The sequencing of social movements. Am Sociol Rev. 1997; 62:779-99.

33. Hager M, Galaskiewicz J, Bielefeld W, Pins J. Tales from the grave: Organizations' accounts of their own demise. Am Behav Sci. 1996;39:975-94.

34. Dart R. Being "business-like" in a nonprofit organization: A grounded and inductive typology. Nonprofit and Voluntary Sector Quarterly. 2004;32:290-310.
Journal of Healthcare Leadership

\section{Publish your work in this journal}

The Journal of Healthcare Leadership is an international, peer-reviewed, open access journal focusing on leadership for the health profession. The journal is committed to the rapid publication of research focusing on but not limited to: Healthcare policy and law; Theoretical and practical aspects healthcare delivery; Interactions between healthcare and society and evidence-based practices;

\section{Dovepress}

Interdisciplinary decision-making; Philosophical and ethical issues; Hazard management; Research and opinion for health leadership; Leadership assessment. The manuscript management system is completely online and includes a very quick and fair peer-review system. Visit http://www.dovepress.com/ testimonials.php to read real quotes from published authors. 